\title{
A Casa e o Museu: análise do Processo de Musealização de Acervos Arquitetônicos Coloniais no Brasil
}

\section{Ariadne Ketini Costa de Alcântara', Maria Letícia Mazzucchi Ferreira²}

\section{Resumo}

Este artigo pretende discutir o processo de musealização de acervos arquitetônicos identificados com o estilo colonial, através do estudo de algumas edificações incorporadas às ações de integração do patrimônio nacional, idealizadas pelo Sphan entre as décadas de 1940 e 1980. Situando nosso estudo nas orientações conceituais da Nova Museologia, abordaremos o desenvolvimento de um painel de debates sobre a interseção entre Museologia e Patrimônio iniciadas na década de 1970, que anunciaram a possibilidade do uso do termo Patrimonialogia.

\section{Palavras-chave}

Musealização; Patrimonialogia; Patrimônio edificado; Arquitetura colonial.

\begin{abstract}
This article refers to the process of musealization of colonial-style architectural events, through the study of some buildings incorporated to the national heritage integration actions, idealized by the domain between the 1980s and 1980s. the development of a panel discussion on an intersection between Museology and Heritage in the 1970s that announced a possibility of using the term Patrimonialogy.
\end{abstract}

\section{Keywords}

Musealization; Patrimonialogy; Built heritage; Colonial architecture.

\section{Introdução}

O projeto de nação elaborado pelas instâncias responsáveis pela agenda cultural do Brasil teve como ápice a criação do Serviço do Patrimônio Histórico e Artístico Nacional (Sphan), em 1937, que instaurou a federalização de ações orientadoras da política cultural no país, tendo como cenário a sedimentação do Estado Novo (1937 a 1945). O Sphan inaugurou um projeto de oficialização do patrimônio nacional, visto outrora de forma fragmentada por representações regionalistas e por instituições que o definiam como um conjunto de manifestações históricas e artísticas eruditas ${ }^{3}$. O anteprojeto de Mário de Andrade, elaborado em 1936 e que serviu de subsídio para a formatação do Decreto-lei $n^{\circ}$ 25/I937, apresentou na sua concepção geral uma noção totalizante da cul-

\footnotetext{
I Doutoranda do Programa de Pós-graduação em Memória Social e Patrimônio Cultural. Pesquisa financiada pela Coordenação de Aperfeiçoamento de Pessoal de Nível Superior (CAPES)

2 Professora Titular da Universidade Federal de Pelotas. Atua como docente e pesquisadora na área de Patrimônio, principalmente nos seguintes temas: patrimônio industrial, patrimônio imaterial, políticas públicas de patrimônio, memória, museus. É docente no Programa de Pós-Graduação (Mestrado/Doutorado) em Memória Social e Patrimônio Cultural da Universidade Federal de Pelotas.

3 Durante a década de 1920 entidades estaduais efetuaram ações de sistematização da política de preservação do patrimônio de caráter nacionalista. Entre os projetos de lei a organização da defesa dos monumentos histórico e artísticos do país, de autoria do pernambucano Luiz Cedro, e a criação de uma Inspetoria Estadual de Monumentos Nacional, do baiano José Wanderley de Araújo Pinho (CHUVA, 2009: I54).
} 
tura brasileira, compreendida como uma unidade cultural produtora de arte patrimonial. A própria noção de patrimônio foi construída nesse período com base em critérios e valores pertinentes às demandas do projeto de nação, o que nos levar a concordar com José Reginaldo Gonçalves (2009: 25) sobre a fundamentação subjetiva do conceito de patrimônio de acordo com os aspectos valorativos das formas tradicionais da cultura.

O texto final do Decreto-lei não sustentou a perspectiva antropológica de Mário de Andrade, que defendia a apreensão do valor universal da cultura em todas as suas formas, costumes e expressões. No entanto, o texto de lei escrito em 1937 assumiu algumas nuances difundidas pelo modernista e ampliou o debate sobre a política de preservação a partir do instrumento jurídico legal nomeado de tombamento. $O$ valor histórico atribuído aos bens móveis e imóveis foi incorporado ao Decreto-lei como fundamento central do tombamento, o que lhes conferia uma condição diferenciada, além da concepção de classificação e registro do patrimônio constante no anteprojeto de Mário de Andrade. $O$ tombamento foi então definido como um dispositivo jurídico que introduziu a possibilidade de modificação do status de propriedades privadas de acordo com sua função social e o interesse público sobre imóveis que carregavam referências históricas ${ }^{4}$. O caráter de oficialização é o aspecto que interessa para nossa análise, uma vez que o "selo" do tombamento federal atribuído pelo Iphan traz implicações que envolvem a reinterpretação do valor de bens culturais, inseridos em uma conjuntura política específica.

Esse texto pretende compreender o processo de patrimonialização de edificações identificadas com o estilo colonial português que foram tombadas como patrimônio nacional entre as décadas de 1940 e 1980. A escolha desses exemplares foi pautada na análise dos efeitos da musealização como estratégia de legitimação patrimonial, considerando as formas narrativas associadas à ideia de identidade nacional, que assumem nos expedientes do lphan a gênese colonial do Brasil. Para fundamentar essa leitura histórica pretendemos investir na verificação de termos e conceitos utilizados para definir um conjunto de práticas associadas a política de preservação de bens culturais, e que podem ser melhor compreendidos se a relação entre patrimônio e museu for mensurada. Iniciaremos nosso debate com uma revisão do termo acervo, pois julgamos que sua aplicação ao patrimônio edificado pode ampliar o léxico de conceitos referentes à museologia.

\section{Acervo arquitetônico: a edificação como documento museal}

A definição da museologia para a palavra acervo está diretamente associada a um conjunto de objetos de caráter particular ou público que são adquiridos de diferentes formas por uma instituição, fazendo assim uma relação direta com a concepção de coleção. André Desvallées e François Mairesse (2013: 33) na obra Conceitos-chave da Museologia, definem coleção a partir da sua estrutura de sentidos, composta por "objetos coletados pelo museu, adquiridos e preservados em razão de seu valor de exemplaridade, de referência, ou como objetos de importância estética ou educativa". A distinção para a palavra acervo é, nesse sentido, contemplada pelos autores através da indicação dos usos e tipologia das coleções, uma vez que tanto na língua francesa como na inglesa não existe uma

4 De acordo com o Decreto-lei $n^{\circ} 25 / 1937$ os bens culturais tombados passaram a ser de interesse público e, portanto, o seu tombamento deveria ser aplicado às pessoas jurídicas do direito privado e de direito público (IPHAN, 2006: 100). 
distinção entre os dois termos. Já entre autores brasileiros o termo acervo é classificado de maneira mais genérica, podendo congregar várias coleções que estão sob a guarda de um museu. $O$ conceito de acervo pode ser entendido ainda através do seu valor documental pois, o registro da sua trajetória, desde sua função original até a aquisição pelo museu, atesta vida social desses objetos.

Recentemente a preocupação com um estudo da terminologia em museologia vem sendo tema recorrente como cita a pesquisadora Diana Farjalla Correia Lima, coordenadora de um projeto que desenvolve a compreensão do vocabulário na perspectiva da Linguagem de Especialidade ou Linguagem Profissional ${ }^{5}$. A distinção da nomenclatura utilizada por profissionais ligados a museologia deve considerar a matriz interdisciplinar que compõe esse campo e, por consequência, as variações semânticas que essas conexões entre áreas do conhecimento produzem. A multiplicidade de sentidos compreendidos nas nomenclaturas aplicadas à museologia pode ser atribuída mais diretamente a intercepção com o campo do Patrimônio, sendo ele próprio gerador de um vasto vocabulário que pode se diversificar de acordo com sua natureza, tipologia, classificação e aplicação. Para Diana Farjalla (2008: 194-195), "situar a ação realizada pela Museologia relacionando-a, adequadamente, no contexto da pluralidade designativa do patrimônio e dos seus correlatos, implica na harmonização terminológica que identifica e reconhece o valor de cunho cultural e social consignado nas diferenças atribuídas aos termos e conceitos que os representam".

A intrínseca relação entre Patrimônio e Museologia pode, partindo das conclusões expostas acima, ser compreendida através do processo de apropriação de conceitos tais como bem cultural, visto em conjunto ou individualmente. $\mathrm{Na}$ perspectiva da Museologia o acervo museológico compreende um conjunto de bens culturais, de caráter material ou imaterial, móvel ou imóvel, que integram o campo documental de objetos/documentos que corresponde ao interesse e objetivo de preservação, pesquisa e comunicação de um museu (BRASIL, 2006). Nesse sentido, quando nos remetemos a modalidade do patrimônio edificado podemos também nos referir a acervo arquitetônico, pois esses bens assumem a qualidade de documento que informa as particularidades de um determinado tempo, estilo arquitetônico, técnica de construção e modos de habitar o espaço. Assim, a musealização pode transformar esse acervo arquitetônico em documento a partir do momento em que é inserido em uma cadeia operativa, que é sistematizada através da aquisição, salvaguarda e comunicação. Parece não haver problemas em aceitar essa afirmativa visto que as próprias ações da patrimonialização indicam um "processo cultural ou o resultado daquilo que remete aos modos de produção e de negociação ligados à identidade cultural, à memória coletiva e individual e aos valores sociais e culturais" (GABRIELE, 20I2: 76). No entanto, as políticas de preservação do patrimônio não contemplam a comunicação com a mesma ênfase da musealização, o que enfraquece o vínculo de identificação da comunidade com o acervo.

A categoria acervo pode lançar luz sobre a musealidade do patrimônio material, estando esse exercício naturalmente relacionado às tipologias do patrimônio móvel e integrado que formam as coleções dos museus ${ }^{6}$. É nesse

5 Diana Farjalla Correia Lima é professora associada da Universidade do Rio de Janeiro, e desenvolve junto ao Programa de Pós-graduação em Museologia e Patrimônio projetos de pesquisa voltados para a patrimonialização e musealização de bens culturais materiais e imateriais. $O$ subprojeto Linguagem de Especialidade ou Linguagem Profissional está sob o âmbito do projeto Termos e Conceitos da Museologia, desenvolvido desde 2005 com o objetivo de investigar questões envolvendo o campo museológico e sua relação com o Patrimônio.

6 Segundo Desvallées e Mairesse o termo musealidade refere-se ao valor específico que as coisas/objetos 
âmbito conceitual que a proposta do presente texto se aproxima da análise dos processos de musealização do patrimônio edificado, pois entendemos que o uso do termo acervo inclui a edificação e os bens móveis associadas a ela. Por outro lado, o termo acervo arquitetônico deve ser associado a uma lógica patrimonial definida pelo jogo de escalas que classifica o patrimônio em conjunto ou individual. A casa colonial assume, portanto, as dimensões de acervo e coleção na medida em que a intenção do seu processo de musealização é constituir a representação de um período histórico que esteja integrado a fruição do conjunto edificado a sua volta.

A Nova Museologia ${ }^{7}$ incluiu em seu horizonte debates sobre a inclusão social, o que permitiu uma aproximação entre a comunidade e o museu em sua totalidade. Assim, o espaço museal não seria mais definido apenas pela coleção, mas pela totalidade de referenciais culturais que o cerca.A Sociomuseologia de acordo com sua dimensão interdisciplinar possibilitou, portanto, a percepção do patrimônio como um facilitador do desenvolvimento e integração social, o que ampliou as funções das instituições museológicas como protagonistas da preservação, conservação e documentação dessa herança cultural (MOUTINHO, 20।4). Em sua tese de doutorado sobre a musealização do patrimônio edificado, o caso do Museu Vivo da Memória Candanga, Maria Cecília Gabrielle (2012: 43-44) ressalta que de acordo com as premissas da Sociomuseologia é possível,

Pensar a atuação no campo disciplinar da museologia, a relação homem-objeto-cenário possui outra dinâmica de interatividade. O homem participa de forma mais reflexiva nas ações de coleta, de interpretação do patrimônio e do processo de musealização. $\bigcirc$ objeto passa a ser trabalhado com a comunidade. $O$ cenário passa a ser percebido como o lugar onde estas relações acontecem, não importando se é um museu tradicional ou parte do território da cidade, mas é entendido como parte importante da compreensão de seu significado. $O$ trinômio homem-objeto-cenário passa a ser visto como sociedade-patrimônio-território.

O patrimônio edificado pode, portanto, ser definido pela sua capacidade de comunicar significados que são apropriados no processo de musealização como parte do aporte histórico em que se fundamenta o projeto da instituição. As reflexões elencadas acimas nos apresentam os novos rumos que essa interação entre o museu e o seu cenário tomaram a partir da Nova Museologia, no sentido da inclusão da comunidade do entorno nas ações identificação com o museu.A criação de museus no Brasil a partir da década de 1940 não previa uma imediata identificação da população à sua volta com o patrimônio nacional em formação. A política cultural direcionada para os museus a partir da criação do Sphan era dedicada à consagração de uma elite aristocrática, grupo que também fomentava os acervos com coleções de objetos que reforçavam seu status e condição de "protagonistas do projeto de nação coesa".

musealizadas possuem, incluindo o valor de documental. (DESVALLÉES; MAIRESSE, 20I3: 58).

7 Segundo Maria Célia Santos, a Nova Museologia se defini como "um movimento, organizado a partir da iniciativa de um grupo de profissionais, em diferentes países [...] dentro dos sistemas de políticas culturais instituídas, organizando museus, de forma criativa, interagindo com os grupos sociais, aplicando as ações de pesquisa, preservação e comunicação, com a participação dos membros de uma comunidade, de acordo com as características dos diferentes contextos, tendo como objetivo principal utilizar o patrimônio cultural, como um instrumento para o exercício da cidadania e para o desenvolvimento social" (SANTOS, 2009: 13). 


\section{Os museus da Era Rodrigo Mello Franco: “documentos da identidade da nação brasileira?"}

“Museu do Ouro”, imagina-se logo um palácio resplandecente; nada disto, é uma simples casa brasileira do melhor teor, casa mineira, - harmoniosa e pacífica (COSTA, 1995: 384).

Quando, em 1995, Lucio Costa publicou suas memórias na obra Registros de uma Vivência dedicou algumas passagens do livro à descrição dos detalhes que tornavam as cidades mineiras legítimas representantes da arquitetura barroca brasileira. Para o arquiteto a casa brasileira, e por consequência a mineira, era uma espécie de arquétipo ideal de habitação pois conseguia reunir em sua concepção a simplicidade e a austeridade do estilo barroco importado e reinventado na colônia. Embalado pela criação do Sphan, Lucio Costa defendeu na edição de abertura da Revista do Serviço do Patrimônio Histórico e Artístico Nacional a preservação da memória da casa tradicional portuguesa onde se identificavam uma espécie de aurora da arte construtiva, das técnicas e dos saberes de mestres de obras, a quem o arquiteto atribuiu a capacidade de manter a originalidade do estilo colonial (COSTA: 1937: 31-4I).Ao criticar o ecletismo e o "afrancesamento" que principiou a descaracterização do estilo colonial em meados do século XIX, Lucio Costa afirma que a singularidade desse estilo é definido justamente pela geniosidade com que nossos mestres e pedreiros, ofícios repassados a índios e negros, souberam adaptar e reinventar a arquitetura popular portuguesa.

As inquietações de Lucio Costa quanto ao abandando e esquecimento das raízes coloniais dialogavam com o movimento nacionalista de valorização da "Casa Portuguesa" que surgiu na antiga metrópole entre o final do século XIX e a década de 1930. Tendo como principais representantes os arquitetos Raul Lino e Ricardo Severo, esse movimento pretendia "estabelecer paralelos acerca de sua relação com correntes arquitetônicas do passado e novas exigências e possibilidades da modernidade" (BORTOLUCCI, 2009: 54), o que resultou em uma releitura da arquitetura vernácula em Portugal e um estudo da evolução da casa brasileira por profissionais ligados ao Sphan. Ao assumir a presidência do Sphan em 1937, Rodrigo Melo Franco de Andrade cercou-se de intelectuais que compartilhavam desse vocabulário nacionalista que foi aos poucos forjando a identidade do patrimônio edificado no Brasil. $O$ então presidente principiou uma campanha de reconhecimento do barroco como "vínculo de civilização que nos irmana aos povos do Ocidente" (CHUVA, 2003: 3 I3).

As "Minas Setecentistas" foi o cenário da gênese do patrimônio nacional. Melo Franco "conhecedor da história das Minas colonial e apaixonado por seus capítulos mais expressivos”(COSTA, 1991: I33), idealizou e fundou em 1944 o Museu da Inconfidência, "sediado na antiga Casa de Câmara e Cadeia de Ouro Preto, passando a abrigar os despojos dos inconfidentes e peças ligadas ao martírio de Tiradentes, além de obras de Aleijadinho e coleção de mobiliário, talha, imaginária e pintura barroca"(ABREU, 1996: 57). Traduzindo a vontade de musealizar o passado da nação Melo Franco se responsabilizou pela,

Formulação de uma política cultural na área do patrimônio e dos museus brasileiros, privilegiando uma concepção histórica [...] entendida enquanto construção nacional na linha do tempo, onde os sujeitos eram as elites (geralmente agentes do Estado), em direção ao progresso e à civilização (ABREU, Op. Cit.). 
A musealização do patrimônio nacional na chamada fase heroica do Iphan, utilizou a casa como suporte de memória e conseguiu articular a narrativa histórica que envolvia os objetos que ilustravam os modos de vida na colônia como os contextos sociais, políticos e econômicos. Como consequência, a casa se transformou em documento por decreto, sem considerar as apropriações efetivas da população. Assim, por meio do Decreto presidencial $n^{\circ} 7.483$ de 16 de maio de 1946, durante o governo Getúlio Vargas, foi inaugurado o Museu do Ouro sediado na antiga Intendência e Casa de Fundição da cidade de Sabará. Desvendando as várias camadas de significados que compõe a trajetória dessa edificação observamos que sua fundação está associada as memórias do Ciclo do Ouro, que dão sentido ao patrimônio local. Segundo o livreto informativo do museu produzido pelo IBRAM,

\begin{abstract}
A Casa de Fundição de Sabará entrou em funcionamento em julho de 1734. Entretanto, já no ano seguinte a Coroa Portuguesa adotou novo sistema de cobrança do Real Quinto, conhecido por Capitação, e as Casas de Fundição foram extintas. Criaram-se, então, nas vilas sedes de Comarca, as Intendências do Ouro. Estabelecida por Carta Régia datada de 28 de janeiro de 1736, a Real Intendência do Ouro de Sabará era uma das mais importantes da região das Minas Gerais devido à sua área de abrangência e volume de produção de ouro. Funcionou de forma autônoma, até 1750, quando nova reestruturação administrativa recria as antigas casas de fundição, integrando-se a elas as já existentes intendências (FIGUEREDO; MENEZES; ROSA, 2017: 23).
\end{abstract}

Após a extinção da Casa de Fundição de Sabará, em 1830, a edificação que outrora estava associada à Coroa portuguesa, é arrematada em leilão, em I840, pelo Comendador Sétimo de Paula Rocha. No hiato entre seu uso residencial pelo Comendador e a criação do museu, foi engendrado um plano de preservação do imóvel que previa o tombamento federal, o que ocorreu em 28 de junho de 1950.

A antiga Intendência de Sabará foi inscrita nos livros de tombo Histórico e de Belas Artes, sendo seu acervo de objetos considerado de "[...] valor histórico e artístico relacionados à indústria da mineração, resgatando, dessa forma, os aspectos principais da sua evolução e técnica, de sua influência no desenvolvimento econômico e na formação social de Minas Gerais e do Brasil" (IPHAN, 1950b: 32).A exposição do Museu do Ouro foi orientada para apresentar a história do Ciclo do Ouro através de "um circuito de exposição de longa duração distribuído por núcleos que representam conceitualmente as funções originais da Intendência de Sabará, as principais técnicas e processos utilizados na extração do ouro e os hábitos e costumes de parte da sociedade mineira do século XVIII" (FIGUEREDO; MENEZES; ROSA, Op. Cit.: 3I). A aquisição do acervo museológico também revela a intencionalidade de constituir um museu de divulgação do patrimônio a partir de uma visão de coesão nacional fomentada por uma história homogênea, que celebrava os grandes vultos políticos e sociais dos períodos colonial e imperial. A maior parte dos objetos foram adquiridos na década de 1940, "por meio de compras e doações de famílias tradicionais do Estado de Minas Gerais, objetos relacionados a costumes sociais e práticas de mineração" (Ibidem, p. 40).

O valor histórico pode ser destacado como orientador da patrimonialização da antiga Intendência de Sabará, uma vez que a narrativa museal da casa 
busca nos capítulos da história setecentista de Sabará a justificativa para sua declaração como patrimônio nacional. O Museu do Ouro ajustou seu discurso histórico com o caráter de excepcionalidade e antiguidade que alguns objetos carregavam, tais como uma prensa de cunhar barras de ouro, datada de 1670, e barra de ouro com cerca de um quilo, quinhentos e cinquenta gramas, o maior exemplar da fase colonial.A inscrição do edifício que abriga o Museu do Ouro nos livros de tombo de História e de Belas Artes revela o caráter centralizador da política de preservação do patrimônio que privilegiava elementos de significância nacional. Em Sabará, o processo de patrimonialização que incluiu ações como a criação do museu no antigo sobrado da Intendência, foi efetuado de maneira técnica contando com a participação de arquitetos, historiadores e restauradores que atuaram como agentes seletores dos bens culturais portadores de valor (SPHAN, 1985: I-2). O conjunto de bens de natureza arquitetônica foi constituído, nem Sabará, a partir de "[...] uma de baixa participação das comunidades locais na gestão dos espaços urbanos e particularmente em relação ao patrimônio um processo de distanciamento entre sociedade e os bens tombados" (SOUZA, 2005:3).

As casas coloniais do ciclo do ouro da antiga capitania de Goiás também foram incorporadas ao projeto de cultura nacional do Sphan. Em 1950, Lúcio Costa, então diretor da Divisão de Estudos e Tombamento do SPHAN, escrevia a Rodrigo Melo Franco sobre a necessidade de se "tombar inicialmente a Casa I, mas o conjunto das demais casas com rótula, forro pintado ou oratório, a casa de Câmara e Cadeia minúscula e as curiosas capelas também merecem beneficiar-se com obras de recomposição e proteção" (IPHAN, 1950a: I). Os elementos destacados pelo arquiteto modernista na petição de tombamento forjaram a base do discurso de patrimonialização do conjunto de casas que formavam o núcleo do distrito de Pilar de Goiás, na época distrito do município Itapaçari.As rótulas das casas coloniais de Pilar se converteram na marca de originalidade e autenticidade que definiam o valor artístico e justificava sua inclusão no Livro de Belas Artes.

Os agentes locais a serviço do patrimônio se mobilizaram pelo "[...] reconhecimento desta diretoria (do SPHAN) pela sua iniciativa patriótica no sentido de incorporar ao patrimônio nacional aquela edificação, que constituiu exemplar de excepcional significação e apuramento das obras de arquitetura residencial do país no período colonial" (IPHAN, Ibidem., p. 6). No Termo de Doação de Imóvel, Jerônimo Coimbra Bueno, então governador do Estado de Goiás, refere-se a casa das rótulas como "[...] uma das mais importantes relíquias do ciclo do ouro no Brasil Central, com o qual deparei em uma das habituais viagens de estudo pelo interior de nosso país" (IPHAN, Ibidem., p.7). A articulação entre as esferas federais, estaduais e municipais presentes no processo de tombamento da Casa das Rótulas fica mais nítida quando é citada a intenção de patrimonializar o conjunto arquitetônico e urbanístico da cidade de Pilar de Goiás, o que acabou ocorrendo 1952, partindo daquele conjunto de casas setecentistas como referencial histórico. $O$ discurso recorrente no trâmite do processo aponta para os norteadores da atuação do Sphan enquanto agência constituidora de uma política de preservação do patrimônio, fundamentada no direito de resguardar a bens de valor histórico e artístico para o país. No entanto, no decorrer do processo depreendemos que a noção de valor é revestida de um evidente peso institucional, o que condicionava a avaliação do processo de tombamento de acordo com características artísticas técnicas, limando a identificação com o valor histórico local. 
Em 198I, após quase 30 anos do tombamento da Casa das Rótulas, o Sphan, juntamente com a Fundação Pró-memória, decidiu criar o Museu Casa Setecentista para abrigar uma "exposição de documentos e peças antigas, artesanato e quaisquer outras manifestações culturais da região" (SPHAN/PRÓ-MEMÓRIA, 1981: 16), que mostrava as formas de viver do povo goiano nos séculos XVII e XVII O Boletim n I 2 (SPHAN/PRÓ-MEMÓRIA, Ibidem., p.I8) do SPHAN trouxe um artigo detalhado da proposta do Museu, destacando que,

\begin{abstract}
O acervo do Museu Casa da Princesa é constituído por 5 documentos históricos, 7 fotografias e 894 objetos, confeccionados em materiais diversos, mostrando formas do viver goiano dos séculos $\mathrm{XVIII}$ ao $\mathrm{XX}$, especialmente mobiliário e utensílios sacros e domésticos utilizados nos casarões de fazendas goianas. Fazem parte deste acervo, material arqueológico, esqueletos de animais, cédulas e moedas, máquinas de escrever, instrumentos de tortura da época colonial, palmatórias, carretilha de forca, tear, carros-de-boi, peças de monjolo, um conjunto completo de engenho, móveis, utensílios de mineração e objetos sacros, como imagens de santos, forma para fazer hóstias, oratórios, cruzes e crucifixos. Com um acervo aberto, a forma de aquisição das peças é doação e compra, feitas pelo Sr.Antônio Gomes Tição.
\end{abstract}

O texto do Boletim esclarece as diretrizes da política de museus implantadas pelo Sphan a partir da década de 1980. Diferente da implantação do Museu do Ouro de Sabará, o Museu Casa Setecentista apresentou uma proposta inicialmente alinhada com as ideias da Nova Museologia que começavam a ser divulgadas no Brasil. $O$ artigo cita que o museu de Pilar de Goiás foi organizado pela própria comunidade, que também participou da indicação da restauração da Casa das Rótulas e Casa de Câmara e Cadeia a $7^{\text {a }}$ Diretoria Regional do SPHAN (SPHAN/PRÓ-MEMÓRIA, I98I: 17). Os usos estabelecidos para o museu também refletem um processo de participação da comunidade que, atrelou a mesma às atividades do Clube de Jovens instalado na Casa de Câmara e Cadeia. A identificação do acervo do Museu com as manifestações populares e tradições religiosas de Pilar do Goiás demostram que o plano de criação da instituição traçou uma estratégia aproximação da comunidade com a casa. No entanto, quando partimos para uma análise do seu Plano Museológico percebemos que a projeção da ideia de patrimônio nacional referenciado pela narrativa da história homogênea e coesa ainda tinha força na política de museus na década de 1980 .

O Plano Museológico do Museu Casa da Princesa, nome estabelecido após sua vinculação ao Instituto Brasileiro de Museus (IBRAM) em 2009, esclarece algumas questões da trajetória administrativa da casa. A Portaria $n{ }^{\circ} 230$ de 28 de março de 1976, documento de regulamentação e competência dos Museus e Casas Históricas atreladas a gestão do SPHAN, estabeleceu em seu artigo $4^{\circ}$, a "Casa da Princesa (ou Casa Setecentista ou Casa das Rótulas) como uma das Unidades Museológicas Locais do Grupo III, no Estado de Goiás, juntamente com o Museu de Arte Sacra da Boa Morte (Goiás-GO), sendo o Museu das Bandeiras (Goiás-GO) a Unidade Museológica Sede” (BRASIL, 2009: I0). Essa determinação fomentou uma reprodução dos modelos institucionais de museus centralizados no acervo museológico, e que utilizava a edificação como alegoria para reforçar um discurso expositivo de época. Apesar da participação da comunidade na montagem do Museu Casa da Princesa, a seleção do acervo, exposição e narrativa museológica ainda estava direcionada para abordar uma 
versão da História do Brasil, e da capitania de Goiás, a partir da ótica de uma elite branca, mineradora e aristocrática.

As escolhas ideológicas estabelecidas quando da criação de um museu refletiam, ainda nas décadas de 1970 e 1980, a carga da tradição da política de cultural de museus estabelecidas no projeto de criação do Sphan em 1937. Para analisar esse panorama citaremos o caso da patrimonialização e criação do Museu Casa Histórica de Alcântara, localizado no município de Alcântara, Estado do Maranhão. Conhecido com sobrado n. 7, o edifício que serviu para abrigar o museu foi construído no início do século XIX pelo Comendador José Maria Correia de Souza, rico comerciante português que não chegou a habitar efetivamente a casa. A memória da população de Alcântara está associada a versão histórica divulgada por escritores locais sobre os períodos de ocupação da residência por duas famílias da elite local: os Barões de São Bento, que compraram o sobrado do Comendador, e o comerciante e alfaiate Antônio da Silva Guimarães, que adquiriu o imóvel em 1889.

Toda a literatura produzida sobre a casa indica esses períodos de ocupação oitocentista através de dois regimes de memória, a primeira associada ao passado colonial opulento, momento de consolidação das fortunas de barões ligados a economia agroexportadora ${ }^{8}$. O segundo quadro social é revestido pelo "discurso da decadência" econômica, que incide sobre uma elite republicana que gradualmente abandona a cidade de Alcântara na tentativa de uma diversificação de negócios e investimentos no polo da indústria têxtil incipiente em São Luís ${ }^{9}$. Durante o século $X X$, o antigo casarão colonial experimenta ainda outras condições como o abandono, vivenciado a partir de 1947 com a morte do proprietário Antônio da Silva Guimarães e de institucionalização quando, em 1986, o Governo Federal, através da Secretaria de Cultura do Estado do Maranhão adquiriu "o imóvel e todo o mobiliário, pratarias, vidraria de farmácia, alfaias, peças de vestuário e demais objetos de valor histórico existentes [...] através do decreto $n^{\circ} 93.656$ de 05 de dezembro com a finalidade de instalar uma Casa de Época"lo.

A musealização do sobrado foi iniciada em 1987 quando foi adquirido pelo Instituto do Patrimônio Histórico e Artístico Nacional, passando dezoito anos em obras de adaptação para abrigar o museu.Ao longo desse período de preparação entram em cena diversos profissionais como a museóloga Célia Cursino, responsável pela capacitação dos funcionários e Evelina Grumberg, encarregada da restauração arquitetônica. Quanto ao plano museológico, surge nesse interim uma série de tensões existentes entre atores locais e os agentes especializados do IPHAN, que divergiram sobre a orientação que deveria ser usada para criar o museu. Daniel Ricon Caires (2012) descreve em seu artigo sobre - Museu Casa Histórica de Alcântara que, o processo de institucionalização da casa revelou um campo de disputas presentes nos discursos e representações que embora dialético, excluíam a participação da comunidade do entorno como uma possibilidade de debate. Caires conseguiu identificar através da análise de pareceres e laudos os discursos possíveis sobre o passado histórico da cidade,

8 A produção histórica e literária sobre Alcântara pode ser avaliada a partir das obras de autores como: VIVEIROS, 1977; LIMA, 1998.

9 Alguns autores desenvolveram trabalhos sobre o "discurso da decadência" aplicado a análise histórica da economia maranhense entre os séculos XVIII e XX. Entre eles estão Raimundo José de Sousa Gaioso, Antônio Bernardino Pereira do Lago, Manuel Antônio Xavier, Garcia de Abranches e Francisco de Paula Ribeiro.

10 Retirado do Blog oficial do Museu Casa Histórica de Alcântara. Disponível em: http://museucasaalcantara.blogspot.com/p/o-museu.html.Acesso em 23 de março de 2018. 
e como essas narrativas incidiram na criação do museu.

Entre os grupos que disputaram a representação do passado colonial da cidade de Alcântara através do Museu Casa estiveram de um lado a Comissão Técnica instituída pelo IPHAN, coordenada pela museóloga Célia Corsino que pretendia constituir o museu por meio de sua função social aplicada à comunidade de Alcântara. Segundo Daniel Caires (2012:I6I), Corsino tentou se afastar da "fundação de uma casa de época repleta de objetos mortos, que reafirmava a Alcântara dos tempos dos barões". Constava ainda no lauto técnico da museóloga a indignações sobre a pertinência de um museu casa e sua integração a população alcantarense pois para Corsino,

\begin{abstract}
A simples coleção de objetos antigos não fará do museu uma instituição eficiente e afinada com o seu tempo. Cremos que a montagem de uma casa de época passa pelas indagações: que época? Casa de quem? Não na certa da maioria da população alcantarense de hoje. Será que sacralizar a Alcântara dos tempos dos Barões é o objetivo de um museu da cidade? Certamente não. Não pretendemos fazer um museu réplica da casa dos Guimarães, mas ter todo um universo simbólico concreto, de toda a Alcântara no espaço Museu da Cidade (CORSINO apud CAIRES, idem.).
\end{abstract}

Por outro lado, os membros remanescentes da família Guimarães se aliaram ao perito judicial e colecionador de antiguidades Alfredo Neto Guterres, para defender a criação de um museu casa que reproduzisse o período de opulência em que viveram as ilustres famílias de Alcântara, perfazendo assim uma espécie de panteão da memória dos nobres dos tempos da colônia. Concordando com a afirmação de Ulpiano Meneses sobre a celebração de uma memória "unificada e homogênea (...) formadora de uma imagem e representação de si própria", observamos que o imaginário social que se pretendia estabelecer com a criação de um museu que se restringe ao itinerário da vida dos barões de Alcântara, tinha o objetivo de suprimir as camadas sociais que também fizeram parte daquele processo histórico. Ao final de 18 anos de intervenções, como nos informa Daniel Caires (Op. Cit., p. 163), a versão dos protagonistas da história acabou por ser admitida como viés do futuro plano museológico da casa, o que ocasionou mudanças no projeto de adaptação arquitetônica tendo sido "suprimidos, após a restauração, a área da senzala e outros espaços representativos do cotidiano e trabalho escravo".

\title{
Considerações Finais
}

A política de museus no Brasil teve sua trajetória integrada com a consolidação do Iphan, instituição responsável pela oficialização do patrimônio cultural no país, desde sua fundação até 2009 , quando o Instituto Brasileiro de Museus é criado. A busca por uma identidade nacional homogênea esteve presente em todas as ações que tentaram descobrir a "gênese do povo brasileiro", progredindo da visão enciclopedista dos museus nacionais para a leitura do povo brasileiro por meio do folclore. A redescoberta das raízes da cultura brasileira através da valorização da regionalidade, da excepcionalidade e da autenticidade foi fomentada pelo Modernismo que identificou nos colonos desbravadores do século XVII seu traço mais expressivo. Assim a arquitetura colonial portuguesa se transformou em luso-brasileira para informar a capacidade de reinvenção do povo brasileiro, e reconheceu na cultura barroca sua manifestação mais original. 
Os primeiros bens culturais tombados pelo Iphan anunciavam a matriz da pedra e cal como vertente orientadora da formação do patrimônio nacional. A arquitetura colonial foi, nesse sentido, usada como categoria justificativa para incorporação de edificações que posteriormente passariam por um processo de musealização. A princípio as casas coloniais foram atreladas aos acervos e coleções se tornando exemplares personalistas e etnocêntricos, confirmando o enredo da dominação portuguesa como versão totalizante da história. Para Mário Chagas (2002:63), esses museus celebrativos da memória do poder "tendem a se constituir em espaços pouco democráticos onde prevalece $o$ argumento da autoridade onde o que importa é celebrar o poder ou o predomínio de um grupo social", como ficou visível no caso da exclusão dos espaços trabalho e socialização dos escravos no Museu Casa Histórica de Alcântara.

Constituído como acervo arquitetônico, categoria de análise constante do vocabulário do patrimônio, as casas coloniais não foram abordadas pelas instituições competentes como acervo museológico em sua dimensão enquanto objeto. Embora na década de 1980 o movimento da Nova Museologia tenha começado a influenciar estudiosos brasileiro, e seus planos museológicos já indicassem princípios de integração da comunidade ao processo de criação de museus, ainda era patente a visão universalista da história. Atrelado a Fundação Pró-memória, criada em 1979, a proposta do museu de Pilar de Goiás foi amparada pela atuação do então presidente do Iphan,Aloísio de Magalhães, que foi responsável por um resgate da proposta etnográfica de Mário de Andrade, além de incentivar a democratização da concepção de patrimônio e reconhecimento da diversidade cultural. No caso do Museu Casa da Princesa, o processo de musealização do acervo de peças identificadas com as tradições religiosas e do mundo do trabalho local ainda foram abordadas através do caráter seletivo da memória do poder.

Consideramos, finalmente, que os museus criados na chamada fase heroica do Iphan, identificam-se com as práticas do "Pensamento Barrosiano" que difundiu uma abordagem factual de acervos elitistas e com a apresentação da exposição através de textos factuais que abordam uma realidade social sem reflexão (SANTOS, 1996: 27). O Museu do Ouro de Sabará foi um exemplo da utilização interpretação factual como discurso retórico, utilizando como suporte os vestígios materiais que remetiam ao apogeu do ciclo da ouro mineiro. A antiga Intendência de Sabará, a única ainda preservada no país, foi, nesse sentido, utilizada como dispositivo de reconhecimento da identidade nacional, o que não significa uma efetiva utilização da edificação como recurso museológico pois não identificamos uma interação desse com a comunidade do entorno. A apresentação de uma identidade nacional e integradora, que procurava abrandar os conflitos que demandavam versões da história mais condizentes com a diversidade cultural do Brasil, parece ser o mote dessas instituições que tinham como função central oficializar a memória social da nação.

Referências

ABREU, Regina. Síndrome de museus? Série Encontros e Estudos. Rio de Janeiro, v. 2, n. I, p. 5I-68, 1996.

BORTOLUCCI, Maria Ângela; LOURENÇO, Júlia Maria; MASCARO, Luciana Pelaes. Raul Lino: uma leitura dos projetos das “casas portuguesas”, Oculum Ensaios. Campinas, n. 9, p. 53-65, 2009.

BRASIL. Plano Museológico Museu Casa da Princesa. Técnica Responsável Girlene Chagas Bulhões, 2009. 
BRASIL. Caderno de Diretrizes Museológicas, n. I. Brasília: Minc/DEMU, Belo Horizonte: Secretaria de Estado da Cultura/Superintendência de Museus, 2006.

CAIRES, Daniel Rincon. Entre barões, foguetes e quilombolas: Museu Casa Histórica de Alcântara e a institucionalização de discursos e representações sobre a cidade de Alcântara, Revista Outros Tempos. São Luís, v. 9, n. I 3, p. I49-I 68, 2012. CHAGAS, Mário. Memória e poder: dois movimentos. Cadernos de Sociomuseologia. Porto, vol. 19, n. 19, p. 43-8I, 2002.

CHUVA, Márcia Regina Romeiro. Os arquitetos da Memória: sociogênese das práticas de preservação do patrimônio cultural no Brasil (anos 1930-1940). Rio de Janeiro: Editora UFRJ, 2009.

CHUVA, Márcia Regina Romeiro. Fundando a nação: a representação de um Brasil barroco, moderno e Civilizado. Revista Topoi. Rio de Janeiro, v. 4, n. 7, p. 3|3-33|, 2003.

COSTA, Lucio. Lucio Costa - registro de uma vivência. São Paulo, Empresa das Artes, 1995.

COSTA, Lucio. Documentação Necessária. Revista do Serviço do Patrimônio Histórico e Artístico Nacional. Rio de Janeiro: IPHAN, vol. I, p. 3 I-4 I, 1937.

COSTA, Lygia Martins da. O pensamento de Rodrigo na criação dos museus do IPHAN. In: Ideólogos do Patrimônio Cultural. Cadernos de Debates. Rio de Janeiro: IBPC, I99I.

DESVALLÉES, André; MAIRESSE, François (Orgs.). Conceitos-chave da museologia. São Paulo: Comitê Brasileiro do Conselho Internacional de Museus: Pinacoteca do Estado de São Paulo: Secretaria de Estado da Cultura, 2013.

FIGUEREDO, Andréia Neves; MENEZES, Isabella Carvalho; ROSA, Ricardo Alfredo de Carvalho. Museu do Ouro. Brasília, DF: IBRAM, 2017.

GABRIELE, Maria Cecília Filgueiras Lima. Musealização do Patrimônio Arquitetônico: inclusão social, identidade e cidadania. Museu Vivo da Memória Candanga. Tese de doutorado defendida junto a Departamento de Museologia da Universidade Lusófona de Humanidades e Tecnologia, Lisboa, 2012.

GONÇALVES, José Reginaldo Santos. O patrimônio como categoria de pensamento. In:ABREU, Regina; CHAGAS, Mário (orgs.). Memória e Patrimônio: ensaios contemporâneos. Rio de Janeiro: Lamparina, 2009.

IPHAN. Coletânea de Leis sobre preservação do Patrimônio. Rio de Janeiro: Iphan, 2006.

IPHAN. Pilar de Goiás - casa à rua Cadeia (com rótula e forro pintado). Processo de Tombamento $n^{\circ}$ 0427-T-50. Arquivo Central do IPHAN - Seção Rio de Janeiro, 1950a.

IPHAN. Sabará - casa à rua da Intendência (Museu do Ouro) 1950-199I. Processo de Tombamento $n^{\circ}$ 0429-T-50.Arquivo Central do IPHAN - Seção Rio de Janeiro, 1950b.

LIMA, Diana Farjalla Correia. Museologia, informação, comunicação e terminologia: pesquisa termos e conceitos da museologia (UNIRIO). In: Museu de Astronomia e Ciências Afins - MAST Documentação em Museus /Museu de Astronomia e Ciências Afins- Organização de: Marcus Granato, Claudia Penha dos Santos e Maria Lucia N. M. Loureiro — Rio de Janeiro: MAST, 2008.

LIMA, Carlos de. Vida, Paixão e Morte da Cidade de Alcântara - Maranhão. São Luís: SECMA, 1998.

MOUTINHO, Mário C. Definição evolutiva de Sociomuseologia. Cadernos do CEOM, v. 27, n. 4I, p. 423-427, 2014.

SANTOS, Maria Célia Teixeira Moura. Reflexões sobre a Nova Museologia. Cadernos de Sociomuseologia, v. I8, n. 18, p. 93-139, 2009. 
SANTOS, Maria Célia Teixeira Moura. $\bigcirc$ papel dos museus na constituição de uma "identidade nacional. Anais do Museu Histórico Nacional. v. 28, p. 2 I-37, 1996. SOUZA, Maria Eliza de Campos. O patrimônio histórico edificado em Sabará e as dissonâncias no seu processo de conservação. In: SIMPÓSIO NACIONAL DE HISTÓRIA, 23., 2005, Londrina. Anais do XXIII Simpósio Nacional de História História: guerra e paz. Londrina:ANPUH, 2005.

SPHAN/ Fundação Nacional Pró-memória. Museu do Ouro: um espaço comunitário ligando passado e presente, Boletim Sphan, Brasília: IPHAN, n. 35, p. I-4, 1985.

SPHAN/Fundação Nacional Pró-memória. Casa da Princesa abriga museu de Pilar do Goiás, Boletim Sphan, Brasília: IPHAN, n. I2, p. I7-18, I98I.

VIVEIROS, Jerônimo de. Alcântara no seu passado Econômico, Social e Político. São Luís: Fundação Cultural do Maranhão, 1977. 